\title{
The Nrf2 transcription factor protects from toxin-induced liver injury and fibrosis
}

\author{
Weihua Xu ${ }^{1,4}$, Claus Hellerbrand ${ }^{2}$, Ulrike A Köhler ${ }^{1}$, Philippe Bugnon ${ }^{1}$, Yuet-Wai Kan ${ }^{3}$, Sabine Werner ${ }^{1}$ \\ and Tobias A Beyer ${ }^{1,5}$
}

The liver is frequently exposed to insults, including toxic chemicals and alcohol, viral infection or metabolic overload. Although it can fully regenerate after acute injury, chronic liver damage causes liver fibrosis and cirrhosis, which can result in complete liver failure. In this study, we demonstrate that the NF-E2-related factor 2 (Nrf2) transcription factor protects the liver from acute and chronic toxin-mediated damage. Repair of the liver injury that occurs after a single treatment with the hepatotoxin carbon tetrachloride $\left(\mathrm{CCl}_{4}\right)$ was severely delayed in Nrf2-deficient mice. The defect in repair was accompanied by an enhanced and prolonged inflammatory and profibrotic response. After long-term $\mathrm{CCl}_{4}$ treatment, liver fibrosis was strongly aggravated in the Nrf2 knockout mice and inflammation was enhanced. We demonstrate that these abnormalities are at least in part due to the reduced expression of known and novel Nrf2 target genes in hepatocytes, which encode enzymes involved in the detoxification of $\mathrm{CCl}_{4}$ and its metabolites. These results suggest that activation of Nrf2 may be a novel strategy to prevent or ameliorate toxin-induced liver injury and fibrosis.

Laboratory Investigation (2008) 88, 1068-1078; doi:10.1038/labinvest.2008.75; published online 4 August 2008

KEYWORDS: fibrosis; cirrhosis; oxidative stress; ROS; inflammation

In contrast to other organs, the liver has the unique capability to regenerate after injury. Loss of functional liver tissue by surgery, necrosis induced by toxins, autoimmune disorders, cholestatic or metabolic diseases or viral infections, starts a well-orchestrated process that aims to restore the lost tissue, resulting in full regeneration. However, sustained presence of the damaging insult prolongs the wound healing response, resulting in liver fibrosis and cirrhosis or acute liver failure. ${ }^{1,2}$

Of particular importance for impaired regeneration is permanent oxidative stress caused by toxins, such as ethanol or haloalkanes, which results in excessive damage of hepatocytes through lipid peroxidation and alkylation of proteins, nucleic acids and lipids. ${ }^{3,4}$ Necrotic and apoptotic death of hepatocytes leads to activation of hepatic stellate cells (HSCs). The latter are responsible for enhanced deposition of fibrillar collagen, regular ECM degradation by proteases, and expression of a wide range of cytokines such as transforming growth factor- $\beta$ (TGF- $\beta$ ), which in turn induce liver fibrosis (reviewed by Friedman ${ }^{2,5}$ ). Oxidative stress is generated in the liver by reactive oxygen species (ROS) produced by activated inflammatory cells via $\mathrm{NAD}(\mathrm{P}) \mathrm{H}$ oxidases, metabolic intermediates of xenobiotics, mitochondrial leakage and by the induction of the cytochrome P450 2 oxidase family (Cyp2). ${ }^{4,6}$

To avoid damage by ROS or promotion of fibrosis, the liver has a sophisticated antioxidant defense system. A central role in the defense against oxidative stress has been attributed to NF-E2-related factor 2 (Nrf2). Expression of many antioxidant proteins and detoxifying enzymes such as glutathione $S$-transferases (GSTs), $\mathrm{NAD}(\mathrm{P}) \mathrm{H}$ quinone oxidoreductase 1 (NQO1) and glutamate-cysteine ligase catalytic subunit (GCLC) and modulatory subunit are controlled by this transcription factor. ${ }^{7}$ The family of $\mathrm{Nrf}$ transcription factors comprises, besides $\mathrm{Nrf} 2$, the closely related proteins Nrf1 and Nrf3, as well as p45 NF-E2, Bach1 and Bach2. They activate expression of their target genes by a cis-acting enhancer element, called antioxidant response element. ${ }^{9}$

Recently, our laboratory identified a crucial role of Nrf2 in liver regeneration after partial hepatectomy. ${ }^{10}$ Enhanced oxidative stress caused transient insulin/insulin-like growth factor resistance in Nrf2-deficient hepatocytes, thereby inhibiting efficient liver regeneration. Furthermore, others

\footnotetext{
${ }^{1}$ Department of Biology, Institute of Cell Biology, ETH Zürich, Switzerland; ${ }^{2}$ Department of Internal Medicine I, University of Regensburg, Bavaria, Germany and

${ }^{3}$ Department of Medicine, University of California, San Francisco, CA, USA

Correspondence: Professor Dr S Werner, PhD, Department of Biology, Institute of Cell Biology, ETH Zürich, Hönggerberg, HPM D42, 8093 Zürich, Switzerland.

E-mail: sabine.werner@cell.biol.ethz.ch

${ }^{4}$ Current address: Department of Hepatology and Gastroenterology, the Second Hospital of Shandong University, Jinan City, Shandong Province, China.

${ }^{5}$ Current address: Samuel Lunenfeld Research Institute, Mount Sinai Hospital, Toronto, ON, Canada.
}

Received 17 March 2008; revised 25 June 2008; accepted 28 June 2008 
showed a crucial role of Nrf2 in the protection of hepatocytes from acetaminophen, ${ }^{11,12}$ ethanol ${ }^{13}$ and bile acid toxicity. ${ }^{14}$ Recent reports suggested a role of Nrf2 in the activation of HSC, ${ }^{15}$ and the activity of Nrf2 was dramatically induced by cholestasis. ${ }^{16}$

To further investigate the function of Nrf2 in liver injury and repair and to study its role in liver fibrosis, we subjected Nrf2 knockout and wild-type mice to acute and chronic $\mathrm{CCl}_{4}$-induced liver damage. ${ }^{17}$ Our results revealed a crucial role of Nrf2 in the protection from acute and chronic liver injury. Most importantly, Nrf2 was identified as an important player in the prevention of fibrosis.

\section{MATERIALS AND METHODS Animals}

Mice with targeted disruption of the $n r f 2$ gene were described previously. ${ }^{18}$ Animals were housed and fed according to federal guidelines. All experiments with mice were approved by the local veterinary authorities of Zurich, Switzerland.

\section{$\mathrm{CCl}_{4}$-Induced Acute Liver Injury}

Female Nrf2 knockout and control mice (8- to 10-week-old) were injected i.p. with a single dose of $\mathrm{CCl}_{4}(0.4 \mathrm{mg} / \mathrm{g}$ body weight (BW) in mineral oil; Sigma, Munich, Germany). At different time points after $\mathrm{CCl}_{4}$ injection, they were killed by $\mathrm{CO}_{2}$ inhalation, and livers were harvested. Livers from untreated and mineral oil-treated animals served as controls.

\section{$\mathrm{CCl}_{4}$-Induced Liver Fibrosis}

Six-week-old female mice (Nrf2 knockout and wild-type controls) were treated with 15 doses of $\mathrm{CCl}_{4}(0.2 \mathrm{mg} / \mathrm{g} \mathrm{BW}$ in mineral oil; Sigma) over a time period of 45 days. At $72 \mathrm{~h}$ after the last injection, mice were killed as described above, and livers were harvested. Livers from mice treated with mineral oil only served as control.

\section{Histology, Histomorphometry and Grading}

Livers were fixed overnight in 4\% paraformaldehyde (PFA) in PBS, embedded in paraffin, and sectioned. Sections $(3.5 \mu \mathrm{m})$ were stained with hematoxylin/eosin (HE), Sirius Red (Sigma) or using the Masson trichrome procedure. HE stained sections were photographed (3-5 pictures per animal), and the necrotic area was determined morphometrically.

Hepatic inflammation after long-term $\mathrm{CCl}_{4}$ treatment was graded numerically according to a score proposed by Thompson et al. ${ }^{19}$ The four different scores are as follows: Score 1: Scanty cells present at junction of necrotic zone; Score 2: Cells regularly present; Score 3: Predominantly neutrophils present; Score 4: Predominantly mononuclear cells present.

\section{Serology}

Blood was taken by heart punctuation of mice that had developed $\mathrm{CCl}_{4}$-induced fibrosis or at different time points after a single $\mathrm{CCl}_{4}$ treatment. Following blood coagulation, serum was collected after centrifugation. Serology was determined using standard procedures.

\section{Labeling of Proliferating Cells with 5-bromo-2'- deoxyuridine}

At $2 \mathrm{~h}$ before killing, mice were injected i.p. with $250 \mathrm{mg} / \mathrm{kg}$ 5-bromo-2'-deoxyuridine (BrdU; Sigma). Livers were fixed in $95 \%$ ethanol $/ 1 \%$ acetic acid, embedded in paraffin and sectioned $(3.5 \mu \mathrm{m})$. BrdU-positive cells were subsequently detected by immunohistochemistry using a peroxidasecoupled mouse monoclonal antibody directed against BrdU (Roche, Rotkreuz, Switzerland).

\section{Terminal dUTP Nick-End Labeling Assay}

Terminal dUTP nick-end labeling (TUNEL) assays were performed according to the manufacturer's manual (Roche) using $3.5 \mu \mathrm{m}$ paraffin sections of tissue that had been fixed in $4 \%$ PFA in PBS.

\section{Immunofluorescence and Immunohistochemistry}

Cryosections $(7 \mu \mathrm{m})$ were fixed in methanol. Alternatively, acidic ethanol-fixed paraffin sections $(3.5 \mu \mathrm{m})$ were used. Sections were incubated overnight at $4{ }^{\circ} \mathrm{C}$ with antibodies to ER-MP23 (Abcam, Cambridge, UK), fibronectin (Santa Cruz Biotechnology, Santa Cruz, CA, USA) and Ly6G (BD Pharmingen, Allschwil, Switzerland), diluted in 3\% bovine serum albumin/PBS/0.02\% Tween $20(\mathrm{v} / \mathrm{v})$. After three washes in $\mathrm{PBS} / 0.1 \%$ Tween 20 , sections were incubated with fluorophore-coupled secondary antibodies (Jackson ImmunoResearch Laboratories, West Grove, PA, USA) and nuclei were counterstained with Hoechst (Molecular Probes, Basel, Switzerland). Alternatively, immunocomplexes were detected using biotinylated secondary antibodies (Jackson ImmunoResearch). Signals were visualized using the $A B C$ staining kit (Vector Laboratories, Burlingame, CA, USA).

\section{RNA Isolation and RNase Protection Assay}

Isolation of total RNA and RNase protection assay (RPA) were performed as described. ${ }^{20}$ RPAs were performed in duplicate using RNAs from different experiments. The following templates were used in this study: cDNAs encoding murine GCLC, GST-Ya, GST- $\pi$, NQO $1,{ }^{10}$ collagen $\mathrm{I} \alpha 1$ (Coll-I $\alpha 1)$, glyceraldehyde 3-phosphate dehydrogenase $($ GAPDH $),{ }^{21}$ and tissue inhibitor of matrix metalloproteinase-1 (TIMP- 1$)^{22}$ and nucleotides $1091-1342$ of the TGF- $\beta 1$ cDNA (NM_011577.1).

\section{Semiquantitative RT-PCR and Real-Time RT-PCR}

RNA was isolated as described above and CDNA was generated using the iScript RT kit (Bio-Rad, Rheinach, Switzerland) according to the manufacturer's instructions. Primers for carboxyl esterase (Ces) 1 (NM_021456, forward: $5^{\prime}$-CCTACCCTCCTTTGTGCTAC-3' ${ }^{\prime}$, reverse: $5^{\prime}$-CG GCTGTGTTCATCCTCT-3'), aldehyde oxidase (Aox) 1 (NM_009676, forward: 5'-CAAAGATGGAGAACGGCG-3', 
reverse: $5^{\prime}$-GCACTGATGATAGTTGAACCGT-3') and GAPDH (XM_001473623.1, forward: 5'-CTATGACCACAGTCCAT GC- $3^{\prime}$, reverse: CACATTGGGGGTAGGAACAC-3') were selected using the program DNAMAN 6.030 (Lynnon Corp., Vaureuil-Dorion, QC, Canada). PCR was performed according to standard procedures.

Quantitative real-time RT-PCR was performed with specific primers for Coll-I $\alpha 1$ (forward 5'-CGGGCAGGACTTGGGTA; reverse 5'-CGGAATCTGAATGGTCTGACT applying LightCycler technology (Roche) as described. ${ }^{23}$ Expression of interleukin (IL) $-1 \alpha$, tumor necrosis factor (TNF)- $\alpha$, interferon (IFN)- $\gamma$, TGF- $\beta 1$ and TIMP- 1 was analyzed applying the QuantiTect primer assay according to the manufacturer's instructions (Qiagen, Hilden, Germany). Amplification of cDNA derived from $18 \mathrm{~s}$ rRNA (18s forward $5^{\prime}$-AAACGGC TACCACATCCAAG; $18 \mathrm{~s}$ reverse $5^{\prime}$-CCTCCAATGGATCCT CGTTA) was used for normalization.

\section{Statistical Analysis}

Statistical analysis was performed using the Prism4 statistical program. $P$-values are two-tailed and were calculated using the Mann-Whitney $U$-test. $P$-values to compare variance were calculated using the F-test.

\section{RESULTS}

\section{Nrf2 Protects from Acute $\mathbf{C C l}_{\mathbf{4}}$-Induced Liver Damage}

We recently identified a crucial role of $\mathrm{Nrf} 2$ in liver regeneration after partial hepatectomy. ${ }^{10}$ This regeneration model induces compensatory hyperproliferation of the hepatocytes in the remaining liver with only minimal necrosis. ${ }^{24}$ In contrast, liver damage caused by hepatotoxic chemicals induces compensatory hepatic hyperplasia after severe liver necrosis due to direct damage of hepatocytes and subsequent inflammation. ${ }^{25}$ To determine if $\mathrm{Nrf} 2$ is also protective under these more harmful conditions, we utilized $\mathrm{CCl}_{4}$ as a model hepatotoxic agent that allowed the evaluation of both necrosis and subsequent inflammation ${ }^{26}$ and fibrosis. ${ }^{17}$ Furthermore, acute $\mathrm{CCl}_{4}$ treatment had recently been shown to induce nuclear translocation of $\mathrm{Nrf} 2$ and activation of the Nrf2 target gene heme oxygenase- $1 .^{27}$ However, the functional role of Nrf2 in this injury model was previously unknown.

Nrf2 knockout mice and wild-type controls were injected i.p. with a single dose of $\mathrm{CCl}_{4}$. This treatment causes severe hepatocyte necrosis ${ }^{26}$ (Figure 1a). Histopathological analysis of liver sections revealed similar hepatocellular damage $24 \mathrm{~h}$ after $\mathrm{CCl}_{4}$ injection in mice of both genotypes (Figure 1a, first panel). However, after $48 \mathrm{~h}$, the extent of necrosis in the central zones of the liver appeared stronger in Nrf2 knockout mice (Figure 1a, second panel). Morphometric analysis of the necrotic area confirmed these findings. No significant difference was observed between mice of both genotypes $24 \mathrm{~h}$ after $\mathrm{CCl}_{4}$ injection, suggesting that the lack of Nrf2 does not aggravate the initial injury (Figure 1b). At $36 \mathrm{~h}$ after injury, the necrotic area was already reduced in wild-type mice but not in Nrf2 knockout mice, although the difference between mice of both genotypes was not statistically significant. However, while the necrotic area was further reduced in the wild-type mice $48 \mathrm{~h}$ after injury, no reduction or even a slight increase in the necrotic area was observed in Nrf2 knockout mice at this time point. Thus, only $18 \%$ of the liver area was affected in wild-type mice $v$ s $35 \%$ in Nrf2-deficient mice (Figure 1a and b). Repair of the damage subsequently started in the Nrf2 knockout mice, and $72 \mathrm{~h}$ after $\mathrm{CCl}_{4}$ injection the necrotic area was reduced to a similar extent in wild-type and knockout mice. At 5 days after $\mathrm{CCl}_{4}$ injection, mice of both genotypes had almost completely recovered, and no significant difference in the necrotic area was observed between Nrf2 knockout and wild-type mice (Figure 1a, third panel and b). These findings suggest that repair of the damage is delayed in Nrf2 knockout mice, and this was particularly obvious when the percentage of repaired necrotic area was statistically analyzed in mice of both genotypes (Figure 1b, lower panel). Furthermore, the time course of cell proliferation in the injured liver strengthens this hypothesis (see below).

Mice of both genotypes that were injected with the vehicle (mineral oil) alone did not display any necrotic areas (data not shown).

Serum aminotransferase levels paralleled the histopathological findings (Figure 1c). At $24 \mathrm{~h}$ after $\mathrm{CCl}_{4}$ injection alanine aminotransferase (ALT) levels were similar in wildtype and Nrf2-deficient mice. However, while $36 \mathrm{~h}$ after injury ALT levels dropped in wild-type mice, they remained elevated in Nrf2-deficient mice. At $48 \mathrm{~h}$ after the insult, ALT levels had decreased in both groups; however, serum levels were significantly higher in Nrf2-deficient mice. At 5 days after $\mathrm{CCl}_{4}$ injection ALT serum levels had returned to the levels seen before liver injury in mice of both genotypes. Analysis of aspartate aminotransferase serum activities revealed a similar pattern (data not shown). Together, these results demonstrate that $\mathrm{Nrf} 2$ knockout mice can repair the initial defect, albeit with a significant delay.

In addition to necrosis, hepatocytes may undergo apoptosis in response to $\mathrm{CCl}_{4}$ treatment. TUNEL staining revealed a similar number of apoptotic cells in mice of both genotypes 24 and $48 \mathrm{~h}$ after injury (Figure $1 \mathrm{~d}$ ). Injection of mineral oil alone did not induce apoptosis in wild-type or knockout mice (data not shown). These results demonstrate that Nrf2 did not protect from apoptotic cell death in this injury model.

\section{Delayed Onset of Hepatocyte Proliferation in Nrf2 Knockout Mice After Acute $\mathbf{C C l}_{\mathbf{4}}$-Mediated Liver Damage}

We next determined if the more severe liver damage seen in Nrf2-deficient mice $48 \mathrm{~h}$ after injury results from a delayed onset of hepatocyte proliferation. To address this question, we analyzed liver cell proliferation by incorporation of the nucleotide analogon BrdU. Figure 2a shows BrdU-positive cells $36 \mathrm{~h}$ after $\mathrm{CCl}_{4}$ administration in wild-type $v s$ knockout 


\section{a}
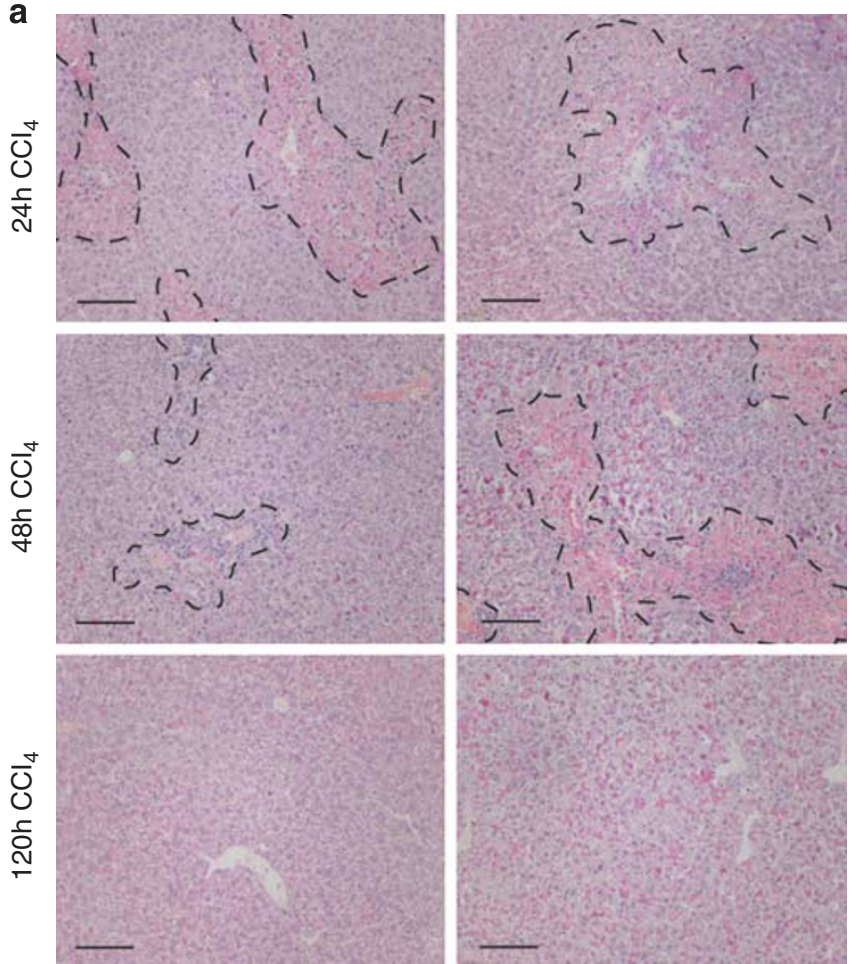

C

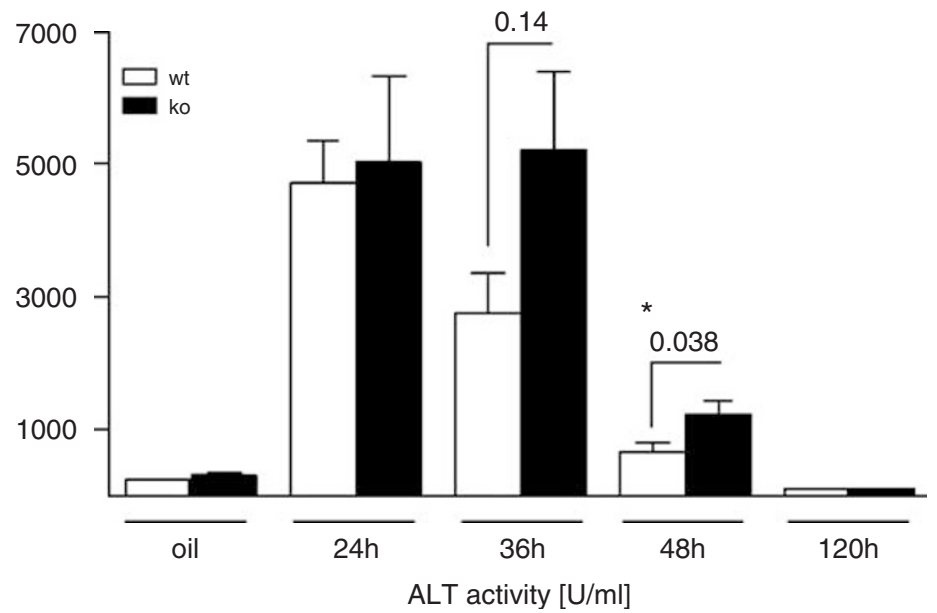

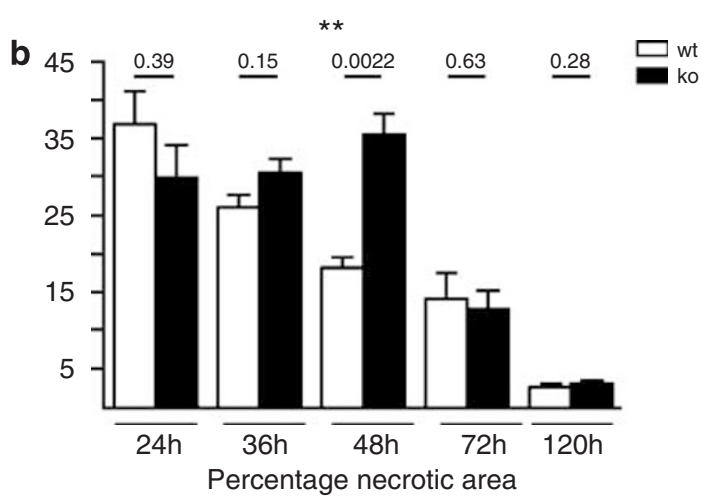

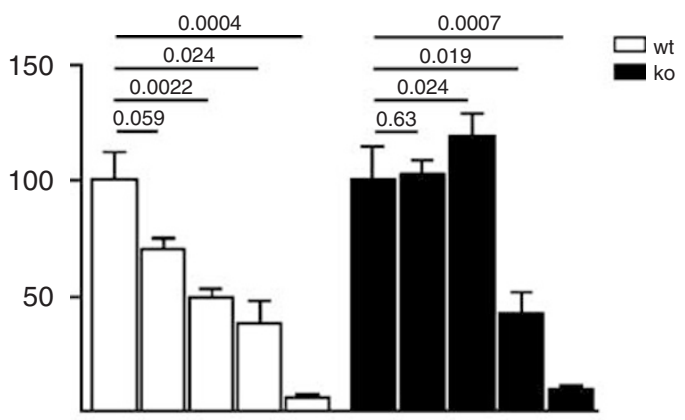

$\overline{24 \mathrm{~h}} \overline{36 \mathrm{~h}} \overline{48 \mathrm{~h}} \overline{72 \mathrm{~h}} \overline{120 \mathrm{~h}} \overline{24 \mathrm{~h}} \overline{36 \mathrm{~h}} \overline{48 \mathrm{~h}} \overline{72 \mathrm{~h}} \overline{120 \mathrm{~h}}$ Kinetics of repair (24h necrotic area set as $100 \%$ )

d

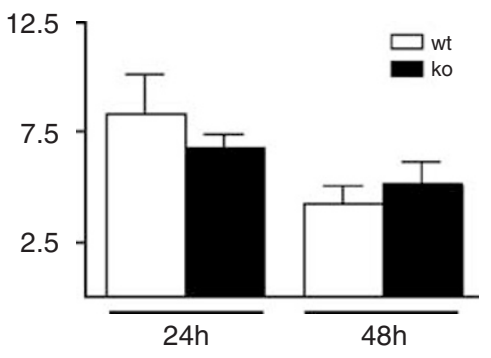

Percentage TUNEL positive cells

Figure 1 Enhanced liver injury in $\mathrm{Nrf2}$ knockout mice after a single injection of $\mathrm{CCl}_{4}$. (a) Mice were killed at different time points after injection of $\mathrm{CCl}_{4}$ in mineral oil or mineral oil alone as indicated. Liver sections were stained with $\mathrm{H} / \mathrm{E}$. Representative sections from wild-type (wt, left panels) and knockout mice (ko, right panel) are shown. Necrotic area can be distinguished from normal liver tissue by the brighter color and by the presence of inflammatory cell infiltrates (encircled areas). Bars indicate $100 \mu \mathrm{m}$. (b) The necrotic area was determined at different time points after $\mathrm{CCl}_{4}$ injection by measuring 3-5 independent microscopic fields per liver and is indicated as percent of total liver area ( $\times 100$ magnification, $N \geq 6$ per genotype for the $24,36,48,72$ and $120 \mathrm{~h}$ time points; $N=3$ wild-type mice for the $72 \mathrm{~h}$ time point and $N=4$ knockout mice for the $72 \mathrm{~h}$ time point). The upper graph shows the percentage of necrotic area in livers of wild-type and knockout mice at each individual time point. The lower graph shows the kinetics of repair in mice of both genotypes. In this case, the necrotic area observed $24 \mathrm{~h}$ after $\mathrm{CCl}_{4}$ injection was set at $100 \%$. (c) The activity of ALT in the serum of wild-type and Nrf2-deficient mice was determined at different time points after $\mathrm{CCl}_{4}$ injection. (d) Apoptotic cells were identified by TUNEL staining. The percentage of TUNEL-positive cells was determined by counting 3-5 independent microscopic fields ( $\times 200$ magnification, $N \geq 6$ per genotype). Bars represent mean \pm s.e.m. $P$-values are indicated in panel $\mathrm{b}$ and $\mathrm{c}$ above the bars. ${ }^{*} P<0.05 ;{ }^{*} P<0.005$.

animals. Figure $2 \mathrm{~b}$ shows quantitation of the percentage of BrdU-positive cells over $120 \mathrm{~h}$ after $\mathrm{CCl}_{4}$ administration. At $24 \mathrm{~h}$ after $\mathrm{CCl}_{4}$ injection, only very few proliferating cells were seen in the liver of wild-type and knockout mice. Twelve hours later ( $36 \mathrm{~h}$ time point), strong proliferation of hepatocytes was seen in most animals of both genotypes, but the extent of hyperproliferation was much more pronounced in the wild-type mice, with up to $36 \%$ of cells being $\mathrm{BrdU}$ positive ( $v s$ a maximum of $20 \%$ in the knockout mice). At 48 and $72 \mathrm{~h}$ after $\mathrm{CCl}_{4}$ injection, the number of BrdU-positive 

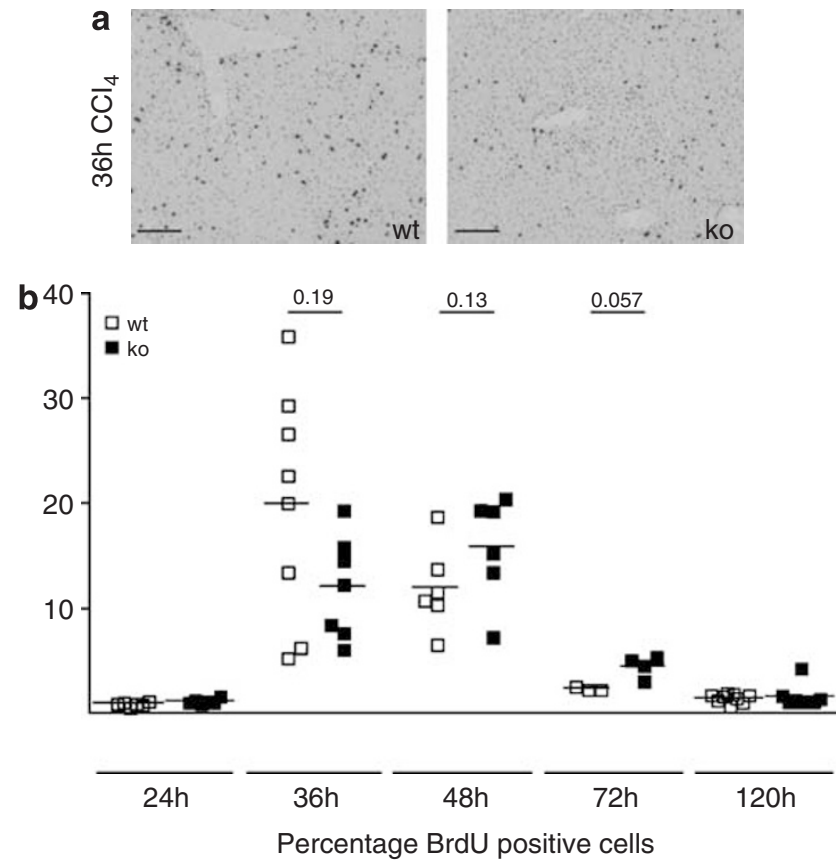

Figure 2 Delayed onset of hepatocyte proliferation in Nrf2 knockout mice after acute $\mathrm{CCl}_{4}$-mediated liver injury. Mice were injected with $\mathrm{BrdU} 2 \mathrm{~h}$ before killing and liver sections were stained with an antibody against BrdU. Representative sections from wild-type and knockout mice $36 \mathrm{~h}$ after injury are shown in (a). Bars indicate $100 \mu \mathrm{m}$. (b) The percentage of BrdU-positive cells was determined by counting 3-5 independent microscopic fields ( $\times 200$ magnification, $N \geq 6$ per genotype for the $24,36,48,72$ and $120 \mathrm{~h}$ time points; $N=3$ wild-type mice for the $72 \mathrm{~h}$ time point and $N=4$ knockout mice for the $72 \mathrm{~h}$ time point). Bars represent mean \pm s.e.m.

cells was (nonsignificantly) higher in the knockout mice compared with wild-type mice. At $120 \mathrm{~h}$ after $\mathrm{CCl}_{4}$ injection (day 5), proliferation had stopped in mice of both genotypes. Although the differences in BrdU positivity at any given time point were not statistically different due to high variability in the number of BrdU-positive cells (in particular in wild-type mice), the data at $36 \mathrm{~h}$ strongly suggest an earlier onset of proliferation in the presence of Nrf2. Indeed, analysis of variance of the dataset supports this hypothesis, as the overall time courses for BrdU positivity in wild-type vs knockout mice were significantly different $(P=0.033)$. In mice treated with mineral oil alone, numbers of BrdU-positive cells were similarly low as in untreated mice at all time points (data not shown).

Taken together, these results strongly suggest that the lack of Nrf2 does not aggravate the initial injury but delays the onset of liver repair after a toxic insult.

\section{Enhanced Expression of Proinflammatory Cytokines and Persistence of Neutrophils After Acute $\mathrm{CCl}_{4}$-Induced Liver Damage}

We next determined if the lack of Nrf2 and thus the reduced detoxification of $\mathrm{CCl}_{4}$ and its metabolites affect the inflammatory response after acute $\mathrm{CCl}_{4}$-mediated liver injury. For this purpose, liver tissue was analyzed at different time points after $\mathrm{CCl}_{4}$ injection for the presence of inflammatory cells. Immunostaining with an antibody against the neutrophil marker Ly6G revealed a strong neutrophil infiltrate in mice of both genotypes at day 1 after injury, reflecting the severe necrosis in the treated liver (Figure 3b). One day later, the number of neutrophils was strongly reduced. No difference in the number of neutrophils was seen between wild-type and knockout mice at these early time points. However, 5 days after $\mathrm{CCl}_{4}$ injection, the number of neutrophils had further decreased in the wild-type mice, whereas it remained elevated in Nrf2 knockout mice (Figure $3 \mathrm{a}$ and $\mathrm{b}$ ). At this time point, the difference in the number of neutrophils was statistically significant (Figure $3 b$ ). The number of macrophages in the injured liver was determined by staining with an antibody against ER-MP23, a macrophage-specific lectin. ${ }^{28}$ Infiltration of these cells peaked $48 \mathrm{~h}$ after $\mathrm{CCl}_{4}$ injection in mice of both genotypes. Macrophages were still present 5 days after the insult. Although their number was slightly higher in the Nrf2 knockout mice, the difference was not statistically significant (data not shown). Mast cells could not be detected at any time point (data not shown).

To determine the reason for the persistence of inflammatory cells, we analyzed the expression of proinflammatory cytokines in injured liver of Nrf2 knockout mice using real-time RT-PCR. For this purpose, we used RNAs that were pooled from at least four mice per time point, and the experiment was repeated with a different set of RNAs from an independent experiment. At $24 \mathrm{~h}$ after injury, levels of IL- $1 \alpha$, TNF- $\alpha$ and IFN- $\gamma$ mRNAs were elevated in mice of both genotypes, but the increase was much higher in Nrf2-deficient mice (Figure 3c-e). Expression levels of these cytokines, in particular of IFN- $\gamma$, were still enhanced in Nrf2 knockout mice compared to controls at later stages after injury, although the difference was much less pronounced compared to the $24 \mathrm{~h}$ time point. Expression of IL- $1 \beta$ also increased after $\mathrm{CCl}_{4}$ injection in mice of both genotypes, and this increase was slightly higher in Nrf2-deficient mice as determined by RNase protection assay (data not shown).

\section{The Profibrotic Response is Enhanced and Prolonged in Nrf2 Knockout Mice After Acute $\mathrm{CCl}_{4}$-Induced Liver Damage}

We next determined if the prolonged tissue injury and inflammation seen in $\mathrm{CCl}_{4}$-treated Nrf2 knockout mice is reflected by upregulation of genes that mediate the fibrotic response. Levels of TGF- $\beta 1$ mRNA were induced $24 \mathrm{~h}$ after $\mathrm{CCl}_{4}$ injection in mice of both genotypes (Figure 4). In addition, expression of the genes encoding Coll-I $\alpha 1$ and TIMP- 1 was induced $24 \mathrm{~h}$ after $\mathrm{CCl}_{4}$ treatment, independent of the genotype (Figure 4). The expression of these genes reflects the onset of tissue remodeling processes, which can lead to fibrosis. ${ }^{29}$ Between 72 and $120 \mathrm{~h}$ after $\mathrm{CCl}_{4}$ injection, expression of these genes strongly declined in the wild-type 

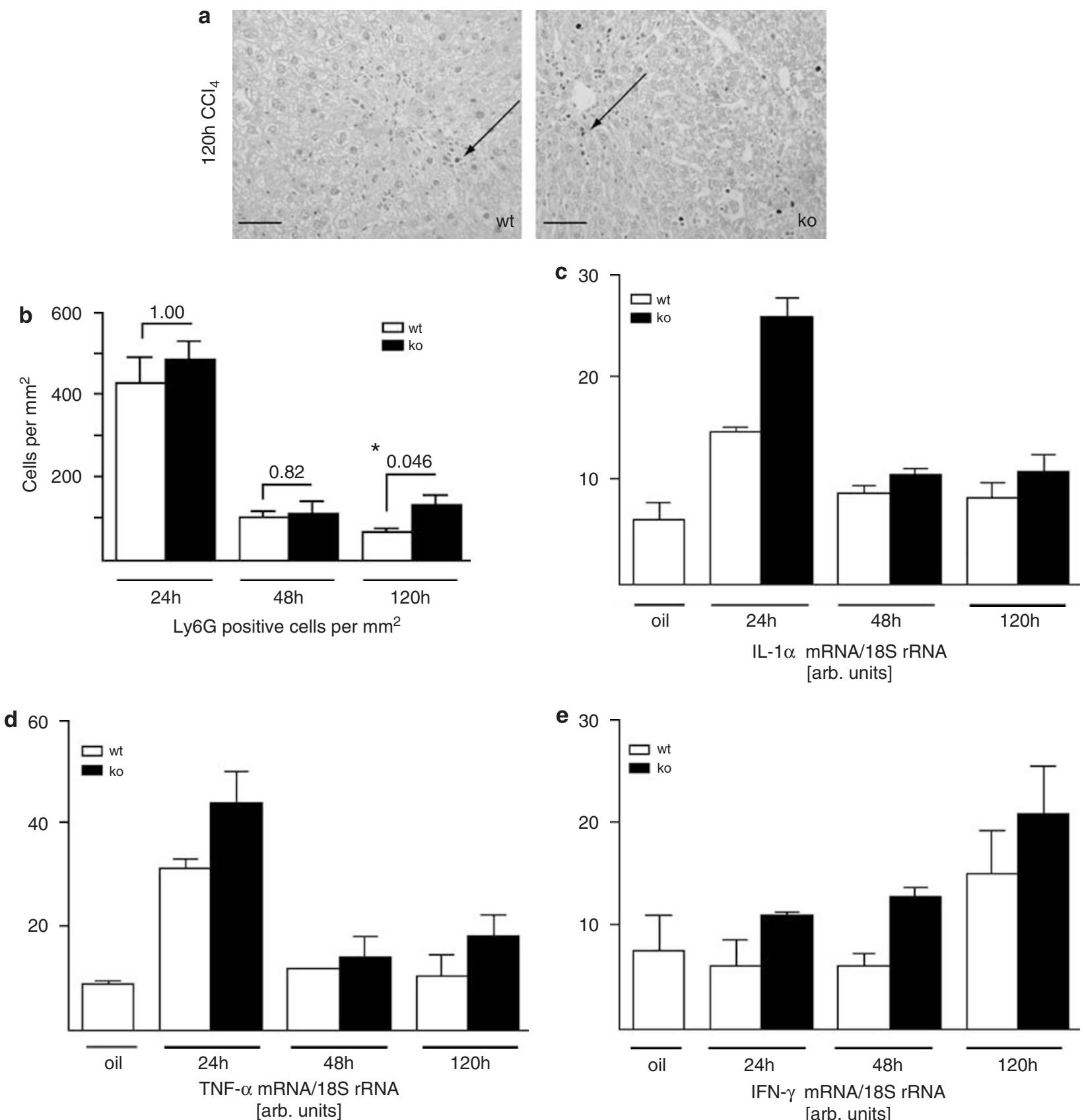

Figure 3 Prolonged inflammation in the liver of Nrf2 knockout mice after a single injection of $\mathrm{CCl}_{4}$. Liver sections were stained with an antibody against the neutrophil marker Ly6G. Representative sections $\left(120 \mathrm{~h}\right.$ after $\mathrm{CCl}_{4}$ injection) are shown in (a). Bars indicate $50 \mu \mathrm{m}$. Quantification of Ly6G-positive cells is shown in (b). Neutrophils were counted in $3-5$ independent microscopy fields ( $\times 200$ magnification, $N \geq 6$ per genotype). Bars represent mean \pm s.e.m.; ${ }^{\star} P<0.05$. (c-e) Expression of proinflammatory cytokines was analyzed in wild-type and Nrf2-deficient mice at different time points after $\mathrm{CCl}_{4}$ injection using real-time RT-PCR. Expression of these cytokines in wild-type mice $24 \mathrm{~h}$ after vehicle (oil) injection is shown for comparison. Two batches of RNAs from independent experiments were used. Amplification of CDNA obtained from $18 \mathrm{~s}$ rRNA was used for normalization. Each RNA sample was pooled from at least four animals. Bars represent mean \pm s.e.m. Note that the values are not statistically significant, as only two batches of RNAs were used. However, each batch of RNA was obtained from pooled liver of at least four animals.

mice but to a much lesser extent in the knockout mice (Figure 4). The data obtained by real-time RT-PCR were confirmed by RNase protection assay (data not shown). These results suggest that livers from Nrf2-deficient animals display a prolonged profibrotic response after $\mathrm{CCl}_{4}$-induced injury.

\section{Nrf2 Protects from $\mathrm{CCl}_{4}$-Induced Chronic Liver Injury}

The prolonged tissue damage, inflammation and profibrotic response that was observed in Nrf2 knockout mice after acute $\mathrm{CCl}_{4}$ injury suggested that the mutant mice are also more prone to chronic liver damage. To address this question, mice 
were subjected to long-term $\mathrm{CCl}_{4}$ treatment $(0.2 \mathrm{mg} / \mathrm{g} \mathrm{BW}$ every third day for 6 weeks), which is known to induce liver fibrosis. ${ }^{17}$ Livers were removed 45 days after the initial injection. Interestingly, the liver weight/body weight ratio was significantly reduced in $\mathrm{CCl}_{4}$-treated knockout mice, but not
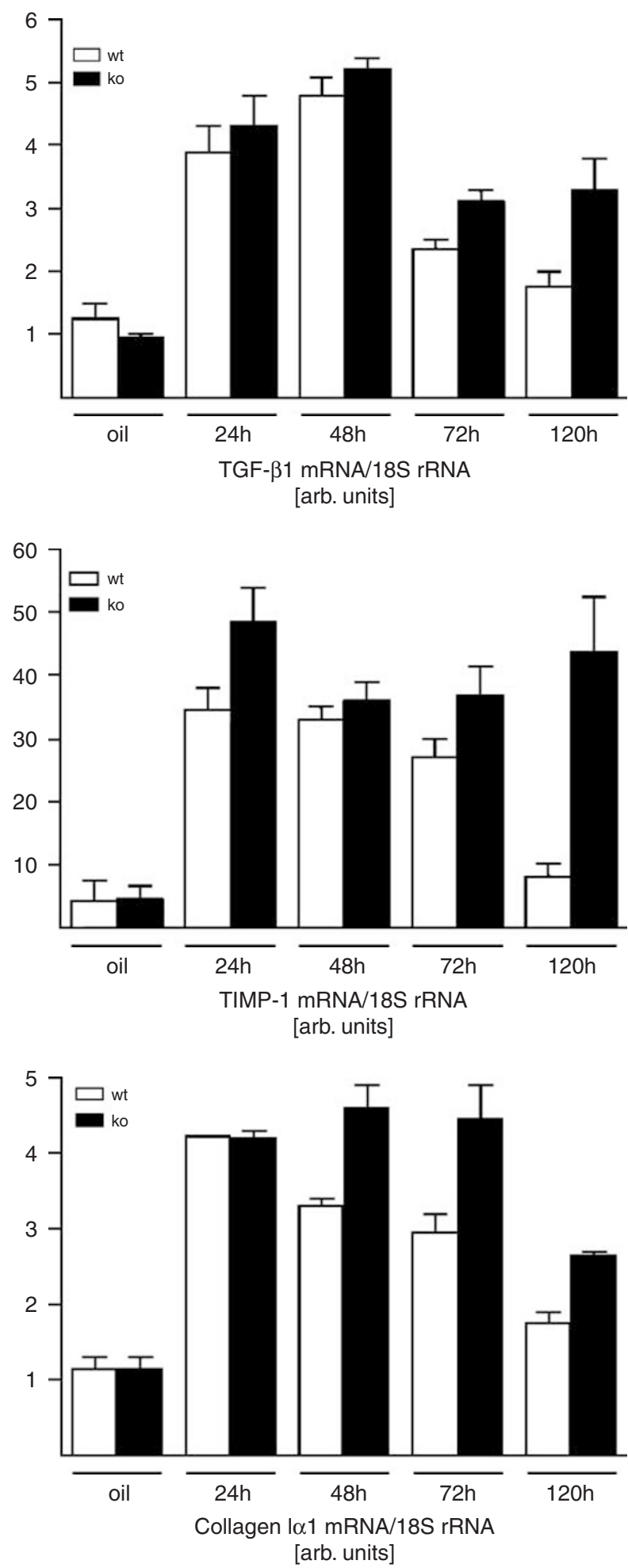

in wild-type littermates or in mineral oil-treated mice of both genotypes (Figure 5a). To determine if this correlates with enhanced liver fibrosis, the fibrotic area was morphometrically determined in Sirius-red-stained sections, where fibrotic tissue can be identified by the red color of the collagen (Figure 5b). In oil-treated mice, fibrosis was not observed and only a small area around blood vessels was stained with Sirius red (Figure 5b), similar as in nontreated mice (data not shown). Upon long-term $\mathrm{CCl}_{4}$ treatment, the percentage of fibrotic area was significantly higher in Nrf2 knockout mice compared to control animals (Figure 5c). This result was confirmed by staining of the sections with Masson trichrome (data not shown, $N \geq 7,{ }^{\star} P=0.04, \quad 1.82 \pm 0.16 \%$ and $2.56 \pm 0.24 \%)$. Further, these findings correlated with more extended deposition of the extracellular matrix protein fibronectin in Nrf2 knockout mice (Figure 5d and e). Expression of Coll-I $\alpha 1$ and of TIMP- 1 was also elevated in fibrotic livers of Nrf2-deficient mice compared to control as determined by real-time RT-PCR (Figure $5 \mathrm{f}$ and $\mathrm{g}$ ). Consistent with the lack of histological abnormalities, upregulation of these genes was not observed in oil-treated mice (Figure $5 \mathrm{f}$ and $\mathrm{g}$ ).

Serum bilirubin levels were increased more than twofold in $\mathrm{CCl}_{4}$-treated $\mathrm{Nrf} 2$ knockout mice compared to wild-type control animals $\left(N \geq 7,{ }^{\star} P=0.018\right.$, data not shown $)$, indicating a more severe defect in liver function.

Finally, histological grading performed by two independent investigators revealed more severe inflammation in $\mathrm{Nrf} 2$ knockout mice compared to control animals (Figure 5h). This finding correlated with increased expression of IL- $1 \alpha$, TNF- $\alpha$ and macrophage chemoattractant protein- 1 in fibrotic liver of the knockout mice as determined by RNase protection assay or real-time RT-PCR (data not shown).

No relevant hepatic fibrosis or inflammation was observed in oil-treated animals of both genotypes (data not shown).

Taken together, these results demonstrate that the lack of Nrf2 aggravates the chronic liver injury and fibrosis that develops after long-term $\mathrm{CCl}_{4}$ treatment.

\section{Decreased Expression of Cytoprotective Nrf2 Target Genes After Acute $\mathrm{CCl}_{4}$-Induced Liver Injury in Nrf2 Knockout Mice}

To gain insight into the mechanisms underlying the enhanced $\mathrm{CCl}_{4}$-induced liver injury in the knockout mice, we

Figure 4 The profibrotic response is prolonged in Nrf2 knockout mice after acute $\mathrm{CCl}_{4}$-mediated liver injury. Expression of genes involved in tissue remodeling was analyzed in wild-type and Nrf2-deficient mice at different time points after $\mathrm{CCl}_{4}$ injection using real-time RT-PCR. Two batches of RNA from independent experiments were used. Expression of these genes in wild-type and Nrf2 knockout mice $24 \mathrm{~h}$ after vehicle (oil) injection is shown for comparison. Amplification of cDNA obtained from $18 \mathrm{~s}$ rRNA was used for normalization. Each RNA sample was pooled from at least four animals. Bars represent mean \pm s.e.m. Note that the values are not statistically significant, as only two batches of RNAs were used. However, each batch of RNA was obtained from pooled liver of at least four animals. 
determined the expression of major Nrf2 target genes. Indeed, expression of GCLC and of NQO1, which are involved in the maintenance of the cellular redox balance, was reduced after acute and chronic liver injury (Figure $6 \mathrm{a}$ and $\mathrm{b}$ ). As ROS play a key role in acute $\mathrm{CCl}_{4}$-induced liver injury, ${ }^{30}$ their reduced detoxification is likely to contribute to the more severe liver injury in Nrf2 knockout mice. In addition, expression of glutathione $S$-transferases, which are involved in the detoxification of $\mathrm{CCl}_{4}$ and its metabolites, was upregulated within $24-48 \mathrm{~h}$ after injection of $\mathrm{CCl}_{4}$ in wild-type mice, but to a much lesser extent in Nrf2-deficient mice. This effect was particularly pronounced for GST-Ya and to a lesser extent for GST- $\pi$ (Figure 6a and b).

Microarray analysis of RNA from noninjured, nontreated liver ${ }^{10}$ and from livers treated with Nrf2 activators ${ }^{31-33}$ of wild-type and Nrf2 knockout mice revealed Ces 1-3, Aox 1 and UDP-glucuronosyl transferase 2 family, polypeptide (ugt2) B35 and B36 as potential targets of Nrf2. These enzymes are involved in the detoxification of $\mathrm{CCl}_{4}$ and its metabolites. ${ }^{3}$ To verify some of these findings, we analyzed the expression of the ces 1 and aox 1 genes by semiquantitative RT-PCR. A slight reduction of ces 1 and aoxl gene expression was observed in resting livers of Nrf2 knockout mice. Most importantly, expression of these genes was much lower in livers of $\mathrm{CCl}_{4}$-treated $\mathrm{Nrf2}$ knockout mice compared to control animals (Figure 6c). These results suggest that enhanced expression of various detoxifying genes in the injured liver reduces $\mathrm{CCl}_{4}$-induced cytotoxicity and that this effect is at least partially mediated by Nrf2.

\section{DISCUSSION}

The Nrf2 transcription factor was previously shown to protect from ROS- and toxin-induced tissue damage through its capacity to induce the expression of genes encoding ROS- and drug-detoxifying enzymes. ${ }^{7}$ The results presented in this study extend these findings to the protection from $\mathrm{CCl}_{4}$-induced liver injury. Most importantly, we provide first evidence for a potent role of Nrf2 in the protection from liver fibrosis/cirrhosis and we identified some of the responsible target genes.

$\mathrm{CCl}_{4}$ treatment is a widely used model to induce liver cell death and, depending on dose and persistence of the insult, liver fibrosis. ${ }^{17}$ The mechanism by which $\mathrm{CCl}_{4}$ exerts its toxicity is well characterized. Members of the cytochrome P450 oxidase family metabolize $\mathrm{CCl}_{4}$ to the trichloromethylfree radical $\left(\mathrm{CCl}_{3}^{\bullet}\right){ }^{34}$ This highly unstable and reactive molecule can directly haloalkylate nucleic acids, proteins and lipids and thereby disturb cell homeostasis. In addition, $\mathrm{CCl}_{3}^{\circ}$ can react with oxygen to form trichloromethyl peroxy radicals $\left(\mathrm{CCl}_{3} \mathrm{OO} \bullet\right)$, which subsequently cause lipid peroxidation. This in turn leads to membrane dysfunction and to accumulation of reactive aldehydes, such as 4-hydroxynonenal. ${ }^{3}$ It has been speculated that detoxification and excretion of reactive aldehydes, haloalkylated macromolecules and other by-products of $\mathrm{CCl}_{4}$ metabolism is dependent on phase II detoxifying enzymes such as GSTs, UDP-glucuronosyl transferases, Aox, Ces and proteins involved in glutathione biosynthesis. ${ }^{35,36}$ Here, we demonstrate that lack of Nrf2 results in aggravated liver damage after a single, nonlethal dose of $\mathrm{CCl}_{4}$. The initial injury was comparable between wild-type and knockout animals, but persisted longer in the latter due to an impaired repair capacity (Figure 1). Expression of detoxifying enzymes such as GST-Ya, GST- $\pi$, GCLC, NQO1, Ces1 and Aox1 peaked $24 \mathrm{~h}$ after injection in wild-type animals, whereas the induction of these enzymes was reduced or completely abrogated in Nrf2-deficient mice (Figure 6a and c). This is likely to result in accumulation and prolonged presence of toxic products of $\mathrm{CCl}_{4}$ metabolism, which in turn inhibit an efficient repair process (Figure 2), perpetuate necrotic cell death and thereby cause prolonged inflammation (Figure 3). The observed phenotype is in accordance with previous studies using acetaminophen as toxin. ${ }^{11,12}$

Interestingly, we observed a prolonged expression of TIMP-1, TGF- $\beta 1$ and Coll-I $\alpha 1$ after a single dose of $\mathrm{CCl}_{4}$. Aberrant expression of these genes in the liver indicates the onset of liver fibrosis. ${ }^{29}$ In addition, oxidative stress, caused by impaired defense against xenobiotics, can lead to the activation of HSCs and thereby to fibrosis. ${ }^{4}$ We therefore further investigated the role of Nrf2 in chemically induced liver fibrosis. Indeed, livers from Nrf2 knockout mice were more susceptible to $\mathrm{CCl}_{4}$-induced fibrosis (Figure 5). Similar to the situation after acute liver injury, reduced basal and inducible expression of Nrf2 target genes was observed, which most likely contributes to the observed pathogenesis (Figure 6b). Thus, it seems likely that reduced detoxification and accumulation of $\mathrm{CCl}_{4}$ metabolites leads to prolonged hepatocyte damage and inflammation, which in turn promotes fibrosis. To further characterize the phenotype, we applied a second model of experimental fibrosis, bile duct ligation (BDL). Some Nrf2 knockout animals also showed high susceptibility to BDL, but with a high degree of variability (data not shown). A likely explanation is provided by the studies of Aleksunes et al. ${ }^{16}$ They showed that despite the induction of Nrf2 target genes by BDL, Nrf2 knockout mice are not suffering from aggravated liver damage, most likely due to a reduced bile production in these animals.

In summary, our results provide a causal link between the reduced expression of cytoprotective proteins and the initiation and progression of liver fibrosis. This is of high clinical importance, as abuse of alcohol or other drugs induces similar damage to the liver as seen in the experimental model of $\mathrm{CCl}_{4}$ intoxication. ${ }^{37}$ In particular, the detoxification of these drugs also requires the action of detoxifying enzymes, which are controlled by Nrf2. Therefore, genetic ${ }^{38}$ or pharmacological activation of $\mathrm{Nrf} 2$ by sulforaphane ${ }^{32}$ or butylated hydroxyanisole ${ }^{33}$ may represent a useful strategy to prevent liver damage after various toxic insults. This hypothesis is supported by the beneficial effect of curcumin on $\mathrm{CCl}_{4}$-mediated liver fibrosis, ${ }^{30}$ which may 
be at least in part mediated through activation of $\mathrm{Nrf2}$ by this polyphenolic antioxidant. ${ }^{39}$ In the future, some of these agents may potentially be used as supportive medication to reduce or even prevent toxin-induced liver fibrosis and possibly also to slow down its progression. Future studies will experimentally address this possibility.
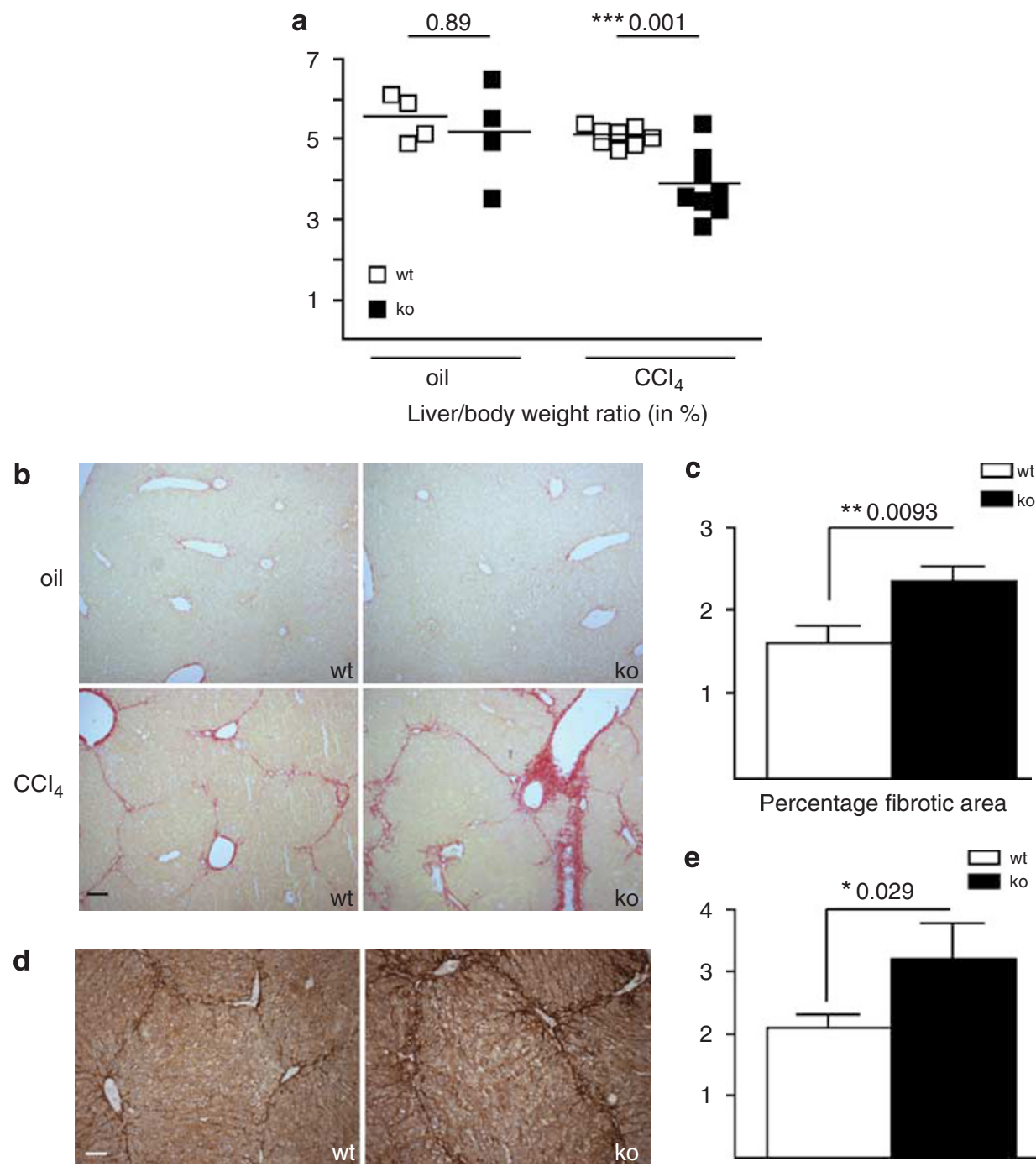

Percentage fibrotic area
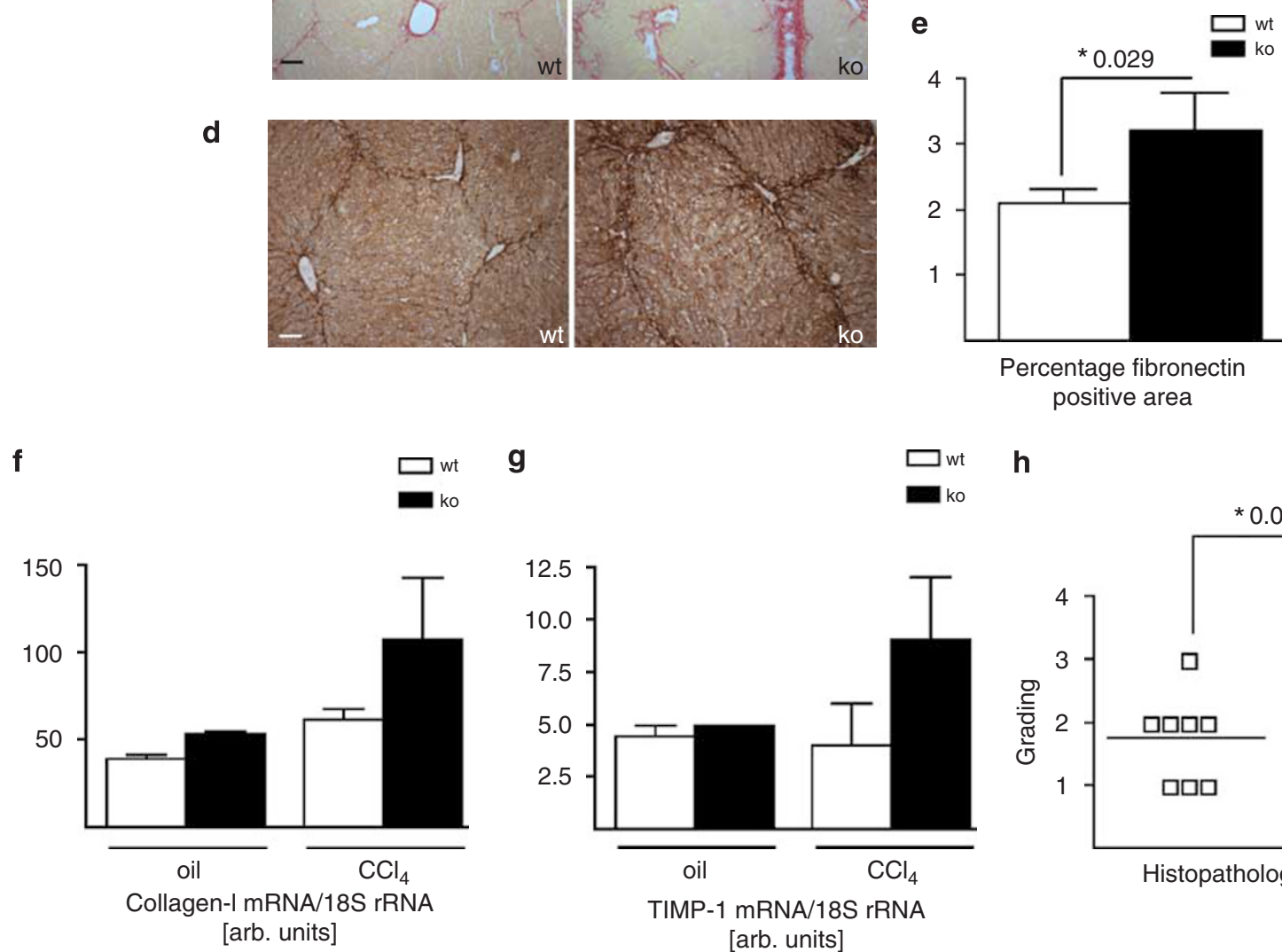

g
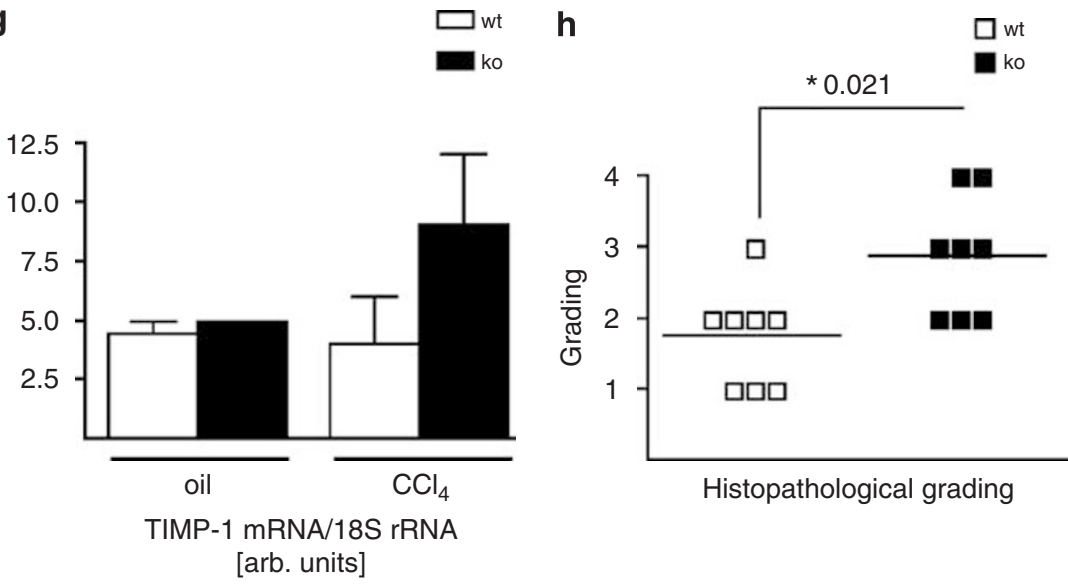

Histopathological grading

[arb. units] 
a

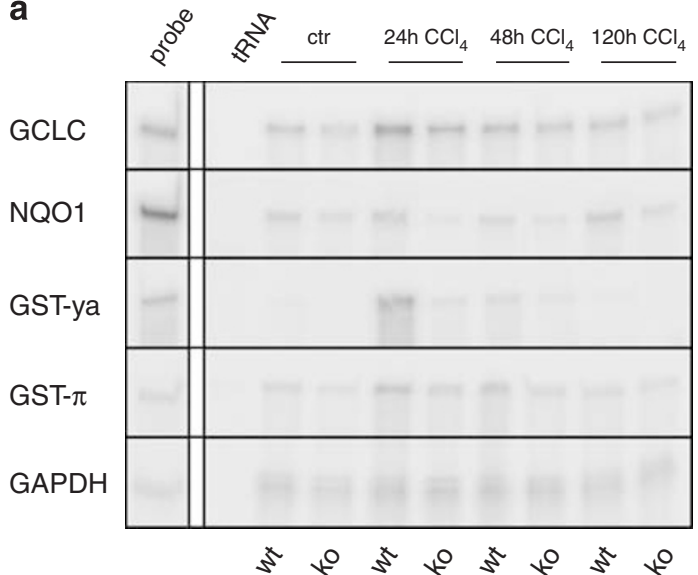

b

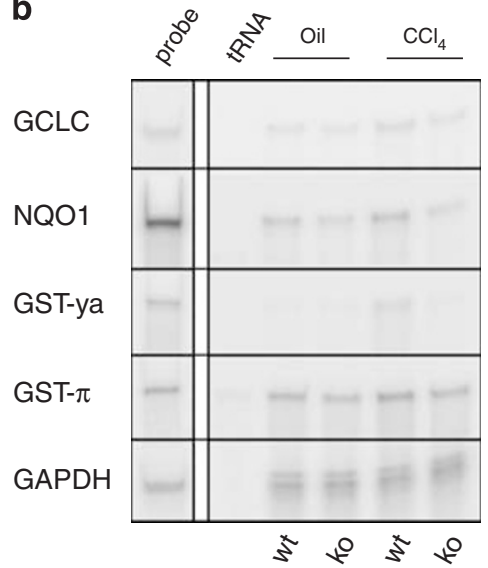

C

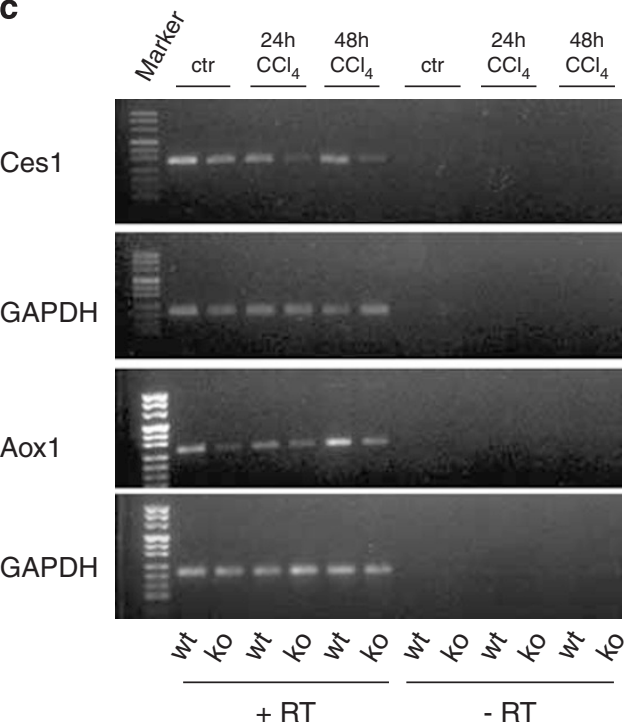

Figure 6 Reduced expression of cytoprotective Nrf2 target genes in Nrf2-deficient mice after acute or chronic liver injury. Samples of $20 \mu \mathrm{g}$ total cellular RNA from the liver of noninjured Nrf2 knockout mice and from liver after short-term (a) or long-term treatment (b) with either mineral oil alone or $\mathrm{CCl}_{4}$ in mineral oil were analyzed by RNase protection assay for the expression of Nrf2 target genes. 1000 c.p.m. of the hybridization probes were loaded in the lanes labeled 'probe' and used as size marker. tRNA ( $20 \mu \mathrm{g})$ were used as a negative control. Hybridization of the samples with a GAPDH riboprobe served as a loading control. (c) RNA samples from livers of Nrf2 wild-type and knockout mice, either untreated or treated for 24 or $48 \mathrm{~h}$ with $\mathrm{CCl}_{4}$, were analyzed by semiquantitative RT-PCR for the expression of carboxyl esterase 1 (Ces1) and aldehyde oxidase 1 (Aox1). Expression levels of GAPDH were used as loading control. +RT: Amplification performed after reverse transcription; -RT: Amplification performed without prior reverse transcription.

Figure 5 Liver fibrosis is aggravated in Nrf2 knockout mice after long-term $\mathrm{CCl}_{4}$ treatment. Mice were subjected to long-term $\mathrm{CCl}_{4}$ treatment as described in 'Materials and Methods'. (a) The liver weight/body weight ratio was determined in $\mathrm{CCl}_{4}$ - or mineral oil-treated Nrf2 knockout mice and wild-type controls $\left(N=4\right.$ per genotype for oil treatment and $N \geq 7$ per genotype for $\mathrm{CCl}_{4}$ treatment. (b) Liver sections were stained with Sirius red. Fibrotic areas appear in red. Bars indicate $100 \mu \mathrm{m}$. (c) The percentage of fibrotic area, which was characterized by the red color of the collagen, was determined in 3-5 independent sections ( $\times 100$ magnification, $N \geq 7$ per genotype). (d) Liver sections were stained with an antibody against the ECM protein fibronectin. Bars indicate $50 \mu \mathrm{m}$. (e) The percentage of the liver area, which was positive for fibronectin, was determined in 3-5 independent sections ( $\times 100$ magnification, $N \geq 7$ per genotype). (f, $\mathbf{g})$ Expression of collagen I $(\alpha 1)$ and of TIMP-1 was analyzed in fibrotic liver of $\mathrm{CCl}_{4}$-treated wild-type and Nrf2-deficient mice as well as in (nonfibrotic) liver of oil-treated animals using real-time RT-PCR. Two batches of RNA from independent experiments were used. Amplification of cDNA obtained from $18 \mathrm{~s}$ rRNA was used for normalization. Each RNA sample was pooled from at least four animals. Bars represent mean \pm s.e.m. (h) Histological grading was performed on $\mathrm{H} / \mathrm{E}$-stained sections by two independent investigators and revealed more severe inflammation in Nrf2 knockout mice compared to control animals $(N=8)$. Individual data points are shown in the scatterplot. Score 1: scanty cells present at junction of necrotic zone; score 2: cells regularly present; score 3: predominantly neutrophils present; score 4: predominantly mononuclear cells present. Bars represent mean \pm s.e.m.; ${ }^{*} P<0.05$, ${ }^{* * P}<0.01,{ }^{* * *} P<0.001$. 


\section{ACKNOWLEDGEMENT}

We thank Christiane Born-Berclaz and Nicole Hallschmid, ETH Zurich, for excellent technical assistance. This work was supported by a grant from the Swiss National Science Foundation (3100A9-109340/1 to SW) and by grants from the German Research Association (He 2458/14-1 and Schn 620/3-1 to $\mathrm{CH})$. WX was employed by the Department of Gastroenterology and Hepatology, the Second Hospital of Shandong University, China, and supported by a scholarship from the China Scholarship Council.

1. Diehl A. Liver regeneration. Front Biosci 2002;7:e301-e314.

2. Friedman SL. Molecular regulation of hepatic fibrosis, an integrated cellular response to tissue injury. J Biol Chem 2000;275:2247-2250.

3. Weber LW, Boll M, Stampfl A. Hepatotoxicity and mechanism of action of haloalkanes: carbon tetrachloride as a toxicological model. Crit Rev Toxicol 2003;33:105-136.

4. Parola M, Robino G. Oxidative stress-related molecules and liver fibrosis. J Hepatol 2001:35:297-306.

5. Friedman SL. Cellular networks in hepatic fibrosis. Digestion 1998;59:368-371.

6. De Minicis S, Brenner DA. NOX in liver fibrosis. Arch Biochem Biophys 2007:462:266-272.

7. Jaiswal A. Nrf2 signaling in coordinated activation of antioxidant gene expression. Free Radic Biol Med 2004;36:1199-1207.

8. Motohashi $\mathrm{H}, \mathrm{O}^{\prime}$ Connor $\mathrm{T}$, Katsuoka $\mathrm{F}$, et al. Integration and diversity of the regulatory network composed of Maf and CNC families of transcription factors. Gene 2002;294:1-12.

9. Nguyen T, Yang C, Pickett C. The pathways and molecular mechanisms regulating Nrf2 activation in response to chemical stress. Free Radic Biol Med 2004;37:433-441.

10. Beyer $T A, X u$ W, Teupser $D$, et al. Impaired liver regeneration in Nrf2 knockout mice: role of ROS-mediated insulin/IGF-1 resistance. EMBO J 2008:27:212-223.

11. Chan K, Han X, Kan Y. An important function of Nrf2 in combating oxidative stress: detoxification of acetaminophen. Proc Natl Acad Sci USA 2001;98:4611-4616.

12. Enomoto $A$, Itoh $\mathrm{K}$, Nagayoshi E, et al. High sensitivity of Nrf2 knockout mice to acetaminophen hepatotoxicity associated with decreased expression of ARE-regulated drug metabolizing enzymes and antioxidant genes. Toxicol Sci 2001;59:169-177.

13. Gong P, Cederbaum A. Nrf2 is increased by CYP2E1 in rodent liver and HepG2 cells and protects against oxidative stress caused by CYP2E1. Hepatology (Baltimore, MD) 2006;43:144-153.

14. Tan KP, Yang M, Ito S. Activation of Nrf2 by toxic bile acids provokes adaptive defense responses to enhance cell survival at the emergence of oxidative stress. Mol Pharmacol 2007;72:1380-1390.

15. Reichard JF, Petersen DR. Involvement of phosphatidylinositol 3-kinase and extracellular-regulated kinase in hepatic stellate cell antioxidant response and myofibroblastic transdifferentiation. Arch Biochem Biophys 2006:446:111-118.

16. Aleksunes LM, Slitt AL, Maher JM, et al. Nuclear factor-E2-related factor 2 expression in liver is critical for induction of $N A D(P) H$ :quinone oxidoreductase 1 during cholestasis. Cell Stress Chaperones 2006;11:356-363.

17. Iredale JP. Models of liver fibrosis: exploring the dynamic nature of inflammation and repair in a solid organ. J Clin Invest 2007;117: 539-548.

18. Chan K, Kan Y. Nrf2 is essential for protection against acute pulmonary injury in mice. Proc Natl Acad Sci USA 1999;96:12731-12736.

19. Thompson K, Maltby J, Fallowfield J, et al. Interleukin-10 expression and function in experimental murine liver inflammation and fibrosis. Hepatology (Baltimore, MD) 1998;28:1597-1606.
20. Werner S, Weinberg W, Liao X, et al. Targeted expression of a dominant-negative FGF receptor mutant in the epidermis of transgenic mice reveals a role of FGF in keratinocyte organization and differentiation. EMBO J 1993;12:2635-2643.

21. Bloch $W$, Huggel K, Sasaki $T$, et al. The angiogenesis inhibitor endostatin impairs blood vessel maturation during wound healing. FASEB J 2000;14:2373-2376.

22. Madlener M, Parks WC, Werner S. Matrix metalloproteinases (MMPs) and their physiological inhibitors (TIMPs) are differentially expressed during excisional skin wound repair. Exp Cell Res 1998;242:201-210.

23. Muhlbauer M, Fleck M, Schutz C, et al. PD-L1 is induced in hepatocytes by viral infection and by interferon-alpha and -gamma and mediates $T$ cell apoptosis. J Hepatol 2006:45:520-528.

24. Taub R. Liver regeneration: from myth to mechanism. Nat Rev Mol Cell Biol 2004:5:836-847.

25. Mehendale HM, Roth RA, Gandolfi AJ, et al. Novel mechanisms in chemically induced hepatotoxicity. FASEB J 1994;8:1285-1295.

26. Huh CG, Factor VM, Sanchez A, et al. Hepatocyte growth factor/c-met signaling pathway is required for efficient liver regeneration and repair. Proc Natl Acad Sci USA 2004;101:4477-4482.

27. Randle $L E$, Goldring $C E$, Benson $C A$, et al. Investigation of the effect of a panel of model hepatotoxins on the Nrf2-Keap1 defence response pathway in CD-1 mice. Toxicology 2008;243:249-260.

28. Dupasquier $\mathrm{M}$, Stoitzner $\mathrm{P}$, Wan $\mathrm{H}$, et al. The dermal microenvironment induces the expression of the alternative activation marker CD301/ $\mathrm{mMGL}$ in mononuclear phagocytes, independent of IL-4/IL-13 signaling. J Leukoc Biol 2006;80:838-849.

29. Iredale JP, Benyon RC, Arthur MJ, et al. Tissue inhibitor of metalloproteinase-1 messenger RNA expression is enhanced relative to interstitial collagenase messenger RNA in experimental liver injury and fibrosis. Hepatology (Baltimore, MD) 1996;24:176-184.

30. Fu $Y$, Zheng $\mathrm{S}$, Lin J, et al. Curcumin protects the rat liver from $\mathrm{CCl}_{4}$ caused injury and fibrogenesis by attenuating oxidative stress and suppressing inflammation. Mol Pharmacol 2008;73:399-409.

31. Hu R, Xu C, Shen G, et al. Identification of Nrf2-regulated genes induced by chemopreventive isothiocyanate PEITC by oligonucleotide microarray. Life Sci 2006;79:1944-1955.

32. Thimmulappa RK, Mai KH, Srisuma S, et al. Identification of Nrf2regulated genes induced by the chemopreventive agent sulforaphane by oligonucleotide microarray. Cancer Res 2002;62:5196-5203.

33. Nair S, Xu C, Shen G, et al. Pharmacogenomics of phenolic antioxidant butylated hydroxyanisole (BHA) in the small intestine and liver of Nrf2 knockout and C57BL/6J mice. Pharm Res 2006;23:2621-2637.

34. Koop DR. Oxidative and reductive metabolism by cytochrome P450 2E1. FASEB J 1992;6:724-730.

35. Fukao T, Hosono T, Misawa $\mathrm{S}$, et al. The effects of allyl sulfides on the induction of phase II detoxification enzymes and liver injury by carbon tetrachloride. Food Chem Toxicol 2004;42:743-749.

36. Fu $\mathrm{Y}$, Zheng $\mathrm{S}$, Lin J, et al. Curcumin protects the rat liver from $\mathrm{CCl}_{4}$ caused injury and fibrogenesis by attenuating oxidative stress and suppressing inflammation. Mol Pharmacol 2008;73:399-409.

37. Albano E. Alcohol, oxidative stress and free radical damage. Proc Nutr Soc 2006;65:278-290.

38. Okawa $H$, Motohashi $H$, Kobayashi $A$, et al. Hepatocyte-specific deletion of the keap1 gene activates Nrf2 and confers potent resistance against acute drug toxicity. Biochem Biophys Res Commun 2006;339:79-88.

39. Shen G, Xu C, Hu R, et al. Modulation of nuclear factor E2-related factor 2-mediated gene expression in mice liver and small intestine by cancer chemopreventive agent curcumin. Mol Cancer Ther 2006;5: 39-51. 